\title{
Und wenn die FMH von Bern nach Zürich umziehen würde?
}

\section{Remo Osterwalder}

Dr. med., Vizepräsident der FMH, Departementsverantwortlicher Dienstleistungen und Berufsentwicklung

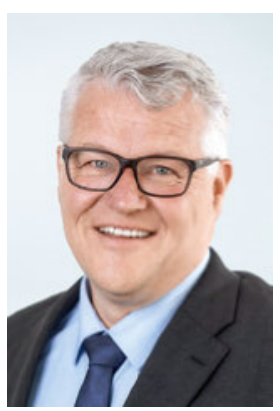

Die Frage ist schon etwas verwegen, aber da ich in der Nordwestschweiz aufgewachsen bin und somit unparteiisch bin, kann ich diese Fragestellung unvoreingenommen untersuchen.

Als ich kürzlich am Paradeplatz stand, war ich beeindruckt von den imposanten Bollwerken der Finanzkunst. Und da wären wir mitten in der Diskussion um die Ärzteschaft: Es geht gemäss Medien und Politikern vor allem ums Geld und die Finanzierung des Gesundheitswesens. Und wer kann besser mit dem Geld umgehen als Finanzspezialisten: 1:0 für Zürich. Da im humanistischen Gesundheitswesen die Frage, ob eine medizinische Massnahme rechtens war, immer häufiger auftritt, ist die Ärzteschaft in verschiedenen Belangen mehr und mehr auf die Unterstützung der Kollegen der Jurisprudenz angewiesen. Auf der Rangliste der renommiertesten Anwaltskanzleien der Schweiz sind die ersten vier Plätze durch Kanzleien belegt, deren Hauptsitz in Zürich liegt. Somit 2:0 für Zürich.

\section{Als Nordwestschweizer darf man die Gretchen- frage «Bern oder Zürich?» stellen.}

Ein weiterer Punkt ist das Platzproblem: Die FMH platzt aufgrund des zunehmenden Bedarfs an Büroräumlichkeiten sprichwörtlich aus allen Nähten und benötigt unbedingt weitere Arbeitsplätze. Im Raum Bern stehen aktuell nur 63000 Quadratmeter Bürofläche leer. Im Gegensatz dazu ist das Raumangebot in Zürich mit 398000 Quadratmetern deutlich grösser. Folglich 3:0 für Zürich. Wenn man die Übersicht verliert, sollte man bekannterweise ein bis zwei Schritte zurücktreten, um das Chaos zu überschauen. Niemand würde bestreiten, dass das politisch entscheidende Epizentrum in Bern liegt. Wie verhält man sich, um dem Tsunami auszuweichen? Indem man sich vom Ufer entfernt und ins Landesinnere flieht. Aus diesem Grund 4:0 für Zürich.
Schauen wir uns noch die theatralische Seite an. Wie im Song "The Show Must Go On" von Queen in der Textpassage besungen: «Another hero, another mindless crime» und "Does anybody want to take it anymore?». Es geht doch um die grosse Show und darum, wer der bessere Showmaster ist. Kein Basler würde mir hier widersprechen, wenn ich behaupte, dass die Zürcher die grössere "Klappe» haben als die Berner (entschuldigt, liebe Zürcher, aber diese Bemerkung konnte ich mir nicht verkneifen). Deshalb geht der Punkt auch hier an Zürich: 5:0.

Hin und wieder macht es Sinn, eine Lagebeurteilung durchzuführen und die Fahrtrichtung entsprechend anzupassen.

Ich bin mir bewusst, dass die Liste nicht vollständig ist und man noch etliche Argumente aufführen könnte. Aber es ging mir primär darum, aufzuzeigen, dass es hin und wieder Sinn macht, eine Lagebeurteilung durchzuführen und die Fahrtrichtung entsprechend anzupassen. Sicher sind radikale Veränderungen eher Hirngespinste. Denn wie könnte man eine über neunzigjährige alte Dame dazu bringen, sich einer Verjüngungskur zu unterziehen. Ich sehe schon die empörten Leserbriefe, weshalb man es auch nur wagen kann, eine über fast ein Jahrhundert entstandene Kultur in Frage zu stellen. Es geht nicht darum, dass man das Rad neu erfindet, aber es sollte sich zumindest drehen, und abgenützte Stellen sollten ersetzt werden. Liebe Berner, denkt nicht, dass ich etwas gegen euch habe. Weit gefehlt, denn ihr habt eine wunderschöne Stadt mit viel Charme und Gemütlichkeit. Auch die Tatsache, dass der direkte Weg in die Wandelhalle viel kürzer von Bern aus ist als von Zürich, spricht für Bern. Keine Angst, das Gefährlichste in Zürich ist und bleibt die Verbrennung des Bööggs mit der nostalgischen Kavallerie. Aber nichtsdestotrotz und frei nach Martin Luther King: I have a dream. 